\title{
ÉTICA NA PESQUISA: 0 TRATO COM O SAGRADO DO OUTRO
}

\section{LARISSA FONTES ${ }^{1}$}

Em minha pesquisa de mestrado, trabalhei com o tema da negociação do segredo ritual no seio das religiões de matriz africana e suas relações com a fotografia. A relação dos pesquisadores com seus interlocutores e a questão da ética na realização das pesquisas também foi uma de minhas grandes preocupações.

O segredo é um elemento que permeia toda a estrutura dessas religiões. É hierarquia, experiência e tempo ${ }^{2}$. Após os ritos iniciáticos, o iaô é introduzido e vinculado à família daquele candomblé, à família de santo. Esse vínculo, segundo Oliveira (2005) se exprime muito mais pelo controle hierárquico da circulação de segredos de culto; os mecanismos propiciatórios de inclusão, de ascensão e evitação dão-se mais por meio de tabus vinculados aos segredos (ou "conhecimentos de fundamentos") do que sob outras formas de tabu. Ser um filho ou filha de santo é submeter-se a um processo de definição de posições hierárquicas. As relações e os graus

1. Doutoranda na Université Lumière Lyon 2 .
2uTempo e hierarquia estão referidos desse modo ao conceito antropológico de seniority, o qual tem a ver com a noção de distinção de geraçães (oposição senionx junion); i esta pode construir-se de modo não automático (imediatamente 'cronológico'), mas através de eventos ordenadamente transcorridos em um grupo, rituais desenvolvidos em uma sequencia periódica dada, que estruturam posiçōes de status, da iniciaçãao, supondo um tempo mínimo até que o filho da Casa possa se candidatar ao próximo evento [não se pode, por exemplo, fazer a obrigaçao de sete anos antes deste tempo, mas e possivel ultrapassar-se os sete anos em muito ate que se venha a fazer dita obrigaçäo; o simples discurso do tempo, sem a realização do rito, não faculta a passagem à condiçăo de sêniori]. A passagem por obrigações define

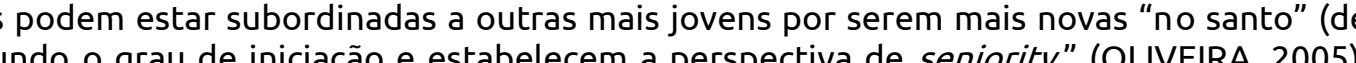
iniciaçăo e obrigaçoes). Enfim: os status se definem segs
Para aprofondar-se nesse aspecto, ver Costa Lima (1977). hierárquicos são garantidos pelo desvelar progressivo de segredos apresentados aos iniciados. "É o que se poderia figurar como as camadas de uma cebola de conhecimentos, a ser descascada a fim de atingir níveis mais profundos no momento propício" (OLIVEIRA, 2005).

O antropólogo José Jorge de Carvalho (1985) afirma que, quase sem exceção, todos os estudiosos dos cultos afro-brasileiros tradicionais já se depararam - e ainda se deparam - com a barreira do segredo, daquilo que não se penetra sem iniciação ou sem um longo período de intimidade e de confiança mútua com o grupo estudado.

Para Carvalho, nosso cuidado, como antropólogos, ao entrarmos em contato com o que chama de "um mundo alternativo de formas simbólicas", deve ser o de preservação da sensibilidade para que não se interfira, nem se provoque a sua desintegração ou desencantamento. A advertência do autor é para que, nós, antropólogos, procuremos diminuir a cada dia mais a distância humana, tão comum no período colonialista da disciplina e que levava à produção de obras para um circulo fechado de acadêmicos, deixando os informantes num mundo separado.

Pierre Verger, por exemplo, o famoso fotógrafo francês radicado na Bahia, foi bastante citado como aquele que sabia muito e calava-se com frequência. Seu biógrafo indica várias situações em que Verger se recusa a participar de projetos que envolvessem revelações dos segredos e mistérios dos candomblés. Seu biógrafo também sinaliza o fato de que hoje, no candomblé, a fotografia se banalizou e a situação não é mais aquela que Verger conheceu: "um 
fotógrafo que respeite o ritual e saiba ser aceito" consegue fotografar rituais e cerimônias (SOUTY, 2001).

Aqui, temos um ponto chave para essa discussão: a confiança. Como nas religiões afrobrasileiras o contato com as divindades e entidades é uma prática através dos jogos oraculares, existe o pressuposto teológico do crivo das próprias divindades e entidades como fator determinante para a realização de pesquisas. Essa dimensão exige uma exposição antropólogo em contrapartida a seu trabalho de pesquisa, numa reciprocidade que qualquer relação humana demanda.

O ensaio aqui publicado foi realizado em três momentos rituais diferentes, reservados e públicos na Serra da Barriga, o quilombo de Zumbi dos Palmares, solo sagrado para os religiosos de matrizes africanas.É um convite à reflexão sobre o trato com o sagrado do outro.

Dois destes rituais foram registrados fazem parte das festividades do 20 de novembro, dia da Consciência Negra. Um deles, embora faça parte das festividades da Consciência Negra, tem um caráter particular, pois não é público como a programação que ocorre durante todo o dia. Os religiosos chegam nas primeiras horas do dia para a realização do axexê, um ritual que celebra a memória dos ancestrais, das centenas de vidas que foram ceifadas no local. É um ritual reservado à comunidade religiosa e exigiu de mim a autorização dos líderes religiosos presentes. Como eu já possuía uma relação de interlocução com praticamente todas as lideranças religiosas presentes, pude registrar o ritual. A confiança foi novamente a chave para a realização de um trabalho.

O segundo momento do dia 20 de novembro não é mais reservado, mas como todo momento ritual, exige uma posição o mais discreta possível, no sentido de não atrapalhar o andamento do ritual nem intimidar os atores. Os religiosos vão à Lagoa dos Negros levar oferendas, ainda saudando os ancestrais.

O terceiro ritual registrado também faz parte de uma realização anual: o dia 6 de fevereiro, em memória ao extermínio do Quilombo dos Palmares.O evento tem início por volta das $22 \mathrm{~h}$ num espaço montado ainda na estrada, no começo da subida que dá acesso ao Parque Memorial do
Quilombo dos Palmares. Após um jantar coletivo, os trabalhos rituais são abertos: antes de tudo, o padê para Exu é despachado

grupo então começa uma peregrinação até o Parque com paradas para intervenções artísticas, apresentações de capoeira e momentos de concentração e oração. Esses momentos não estão presentes no ensaio aqui publicado por motivos da impossibilidade de captação fotográfica causada pela falta de luz. A captação sem auxílio do flash não era possível e foi uma escolha minha não fazer uso desse equipamento, que certamente atrapalharia os momentos rituais e incomodaria as pessoas. Chegando ao Parque, já tarde da madrugada, os religiosos fazem xirês ${ }^{4}$ e, mais uma vez, são realizadas apresentações artísticas de grupos ligados aos terreiros e falas de intelectuais convidados, de líderes religiosos e de organizadores do evento. A programação atravessa a madrugada e termina com um café da manhã.

REFERÊNCIAS

CARVALHO, José Jorge. A Racionalidade Antropológica em Face do Segredo. Anuário Antropológico n. 34, 1985.
FONTES, Larissa. A Dádiva do Segredo: A Negociação do Segredo Ritual nas Religiões Afro-alagoanas. Dissertação de Mestrado. Universidade Federal da Bahia, UFBA. Salvador, Bahia, 2015.

Feitura de Santo - Um Registro do Secreto. Faculdade Integrada Tiradentes, Maceió, 2012. OLIVEIRA, Rafael Soares de. O feitiço de Oxum. Um estudo subre o llê Axé lyánassôôká e suas relaçóes em rede com outros terreiros.
Tese (Doutorado apresentada ao Programa de Pós-Graduação em Ciências Sociais da Universidade Federal da Bahia). Salvador: SOUTY, Jérôme. Pierre Fatumbi Verger: do olhar livre ao conhecimento iniciático. Tradução Michel Colin. São Paulo: Editora Terceiro Nome, 2011.

${ }^{3}$ Todos os rituais realizados no Candomblé, públicos ou internos, são necessariamente precedidos do Padê de Exu, uma cerimonia que consiste
em homenagear o orixá mensageiro, para que ele leve a mensagem aos outros orixás; avise-os de que alí estão precisando de sua presença. Na prática, são despejados na porta do terreiro um prato de farofa de dendê e uma talha (ou quartinha, pequeno reservatório de barro comum nesses cultos) de água, em algumas situaçōes com sal. O Padêé popularmente - e equivocadamente - conhecido pela expressão "despachar céu dos orixás (Orun). (FONTES, 2012) ${ }^{4}$ Roda de dança e canto rituais. 

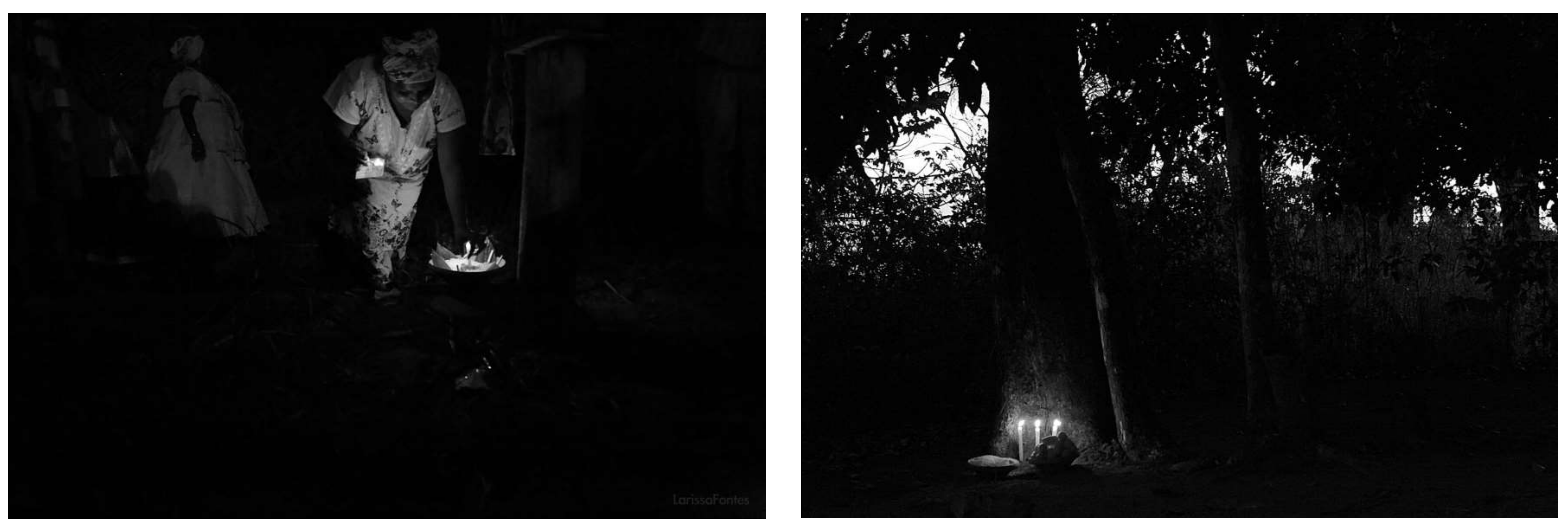


\section{*}

in

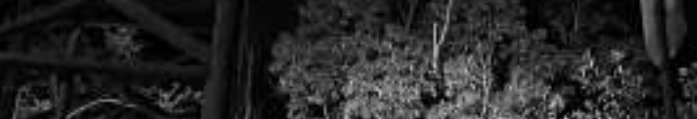

maxicas

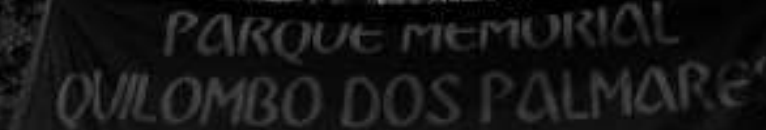
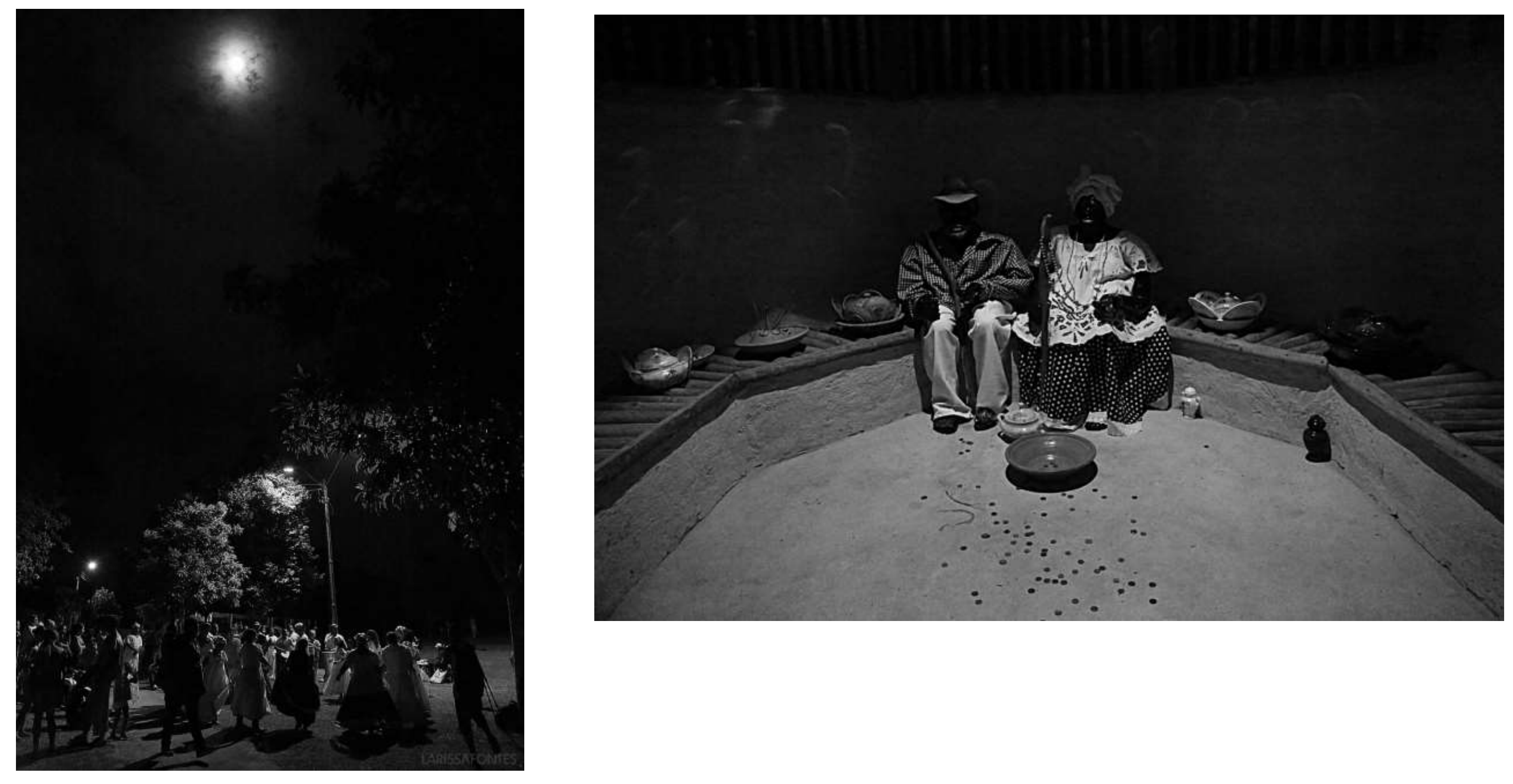

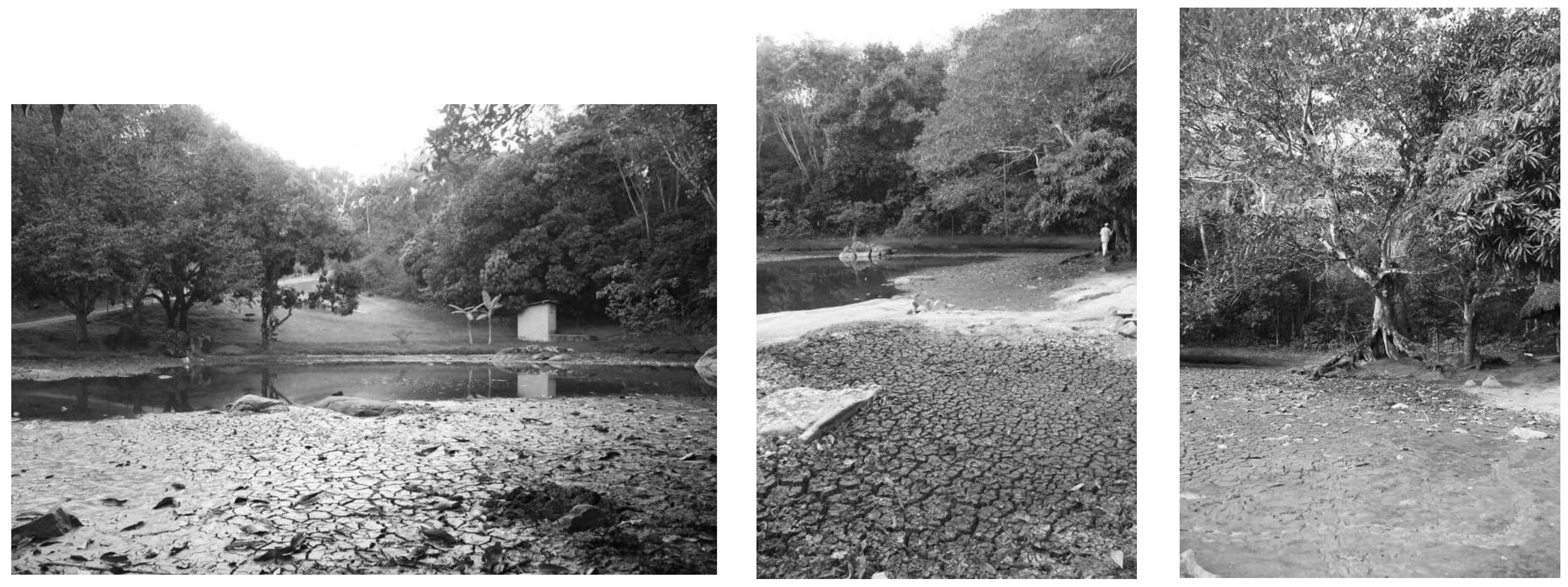

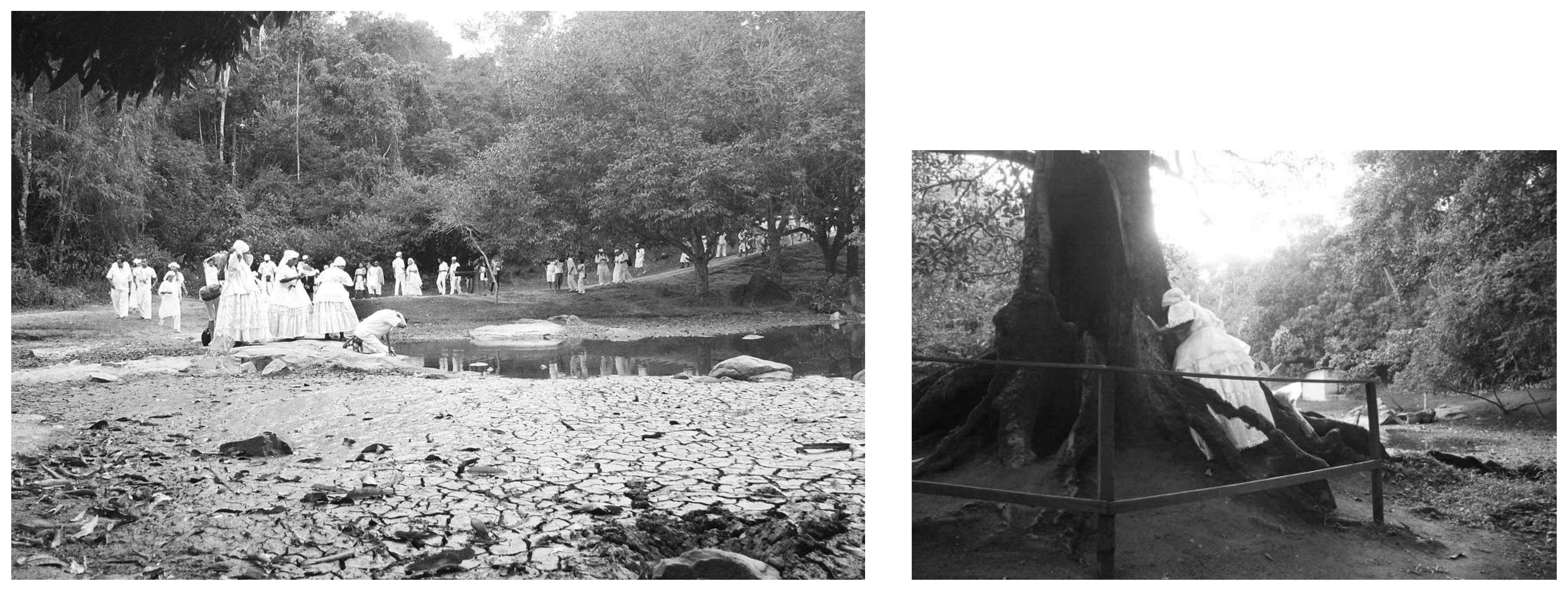

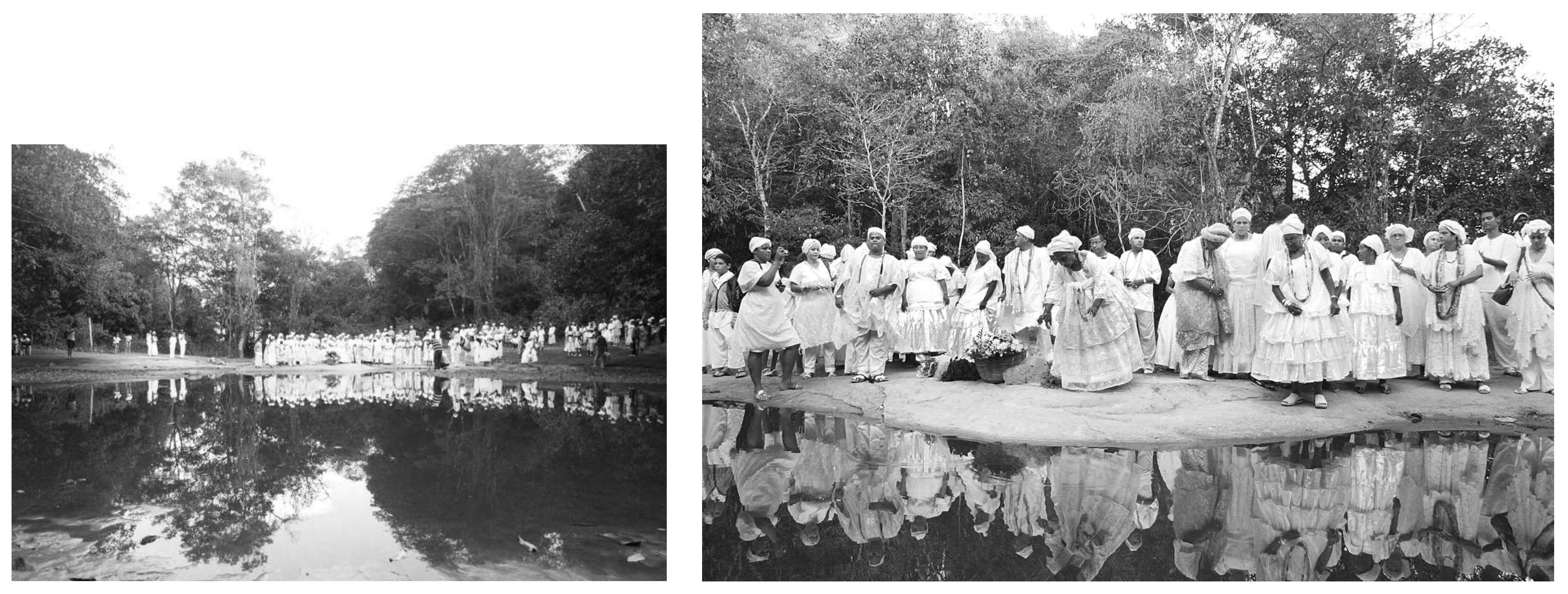

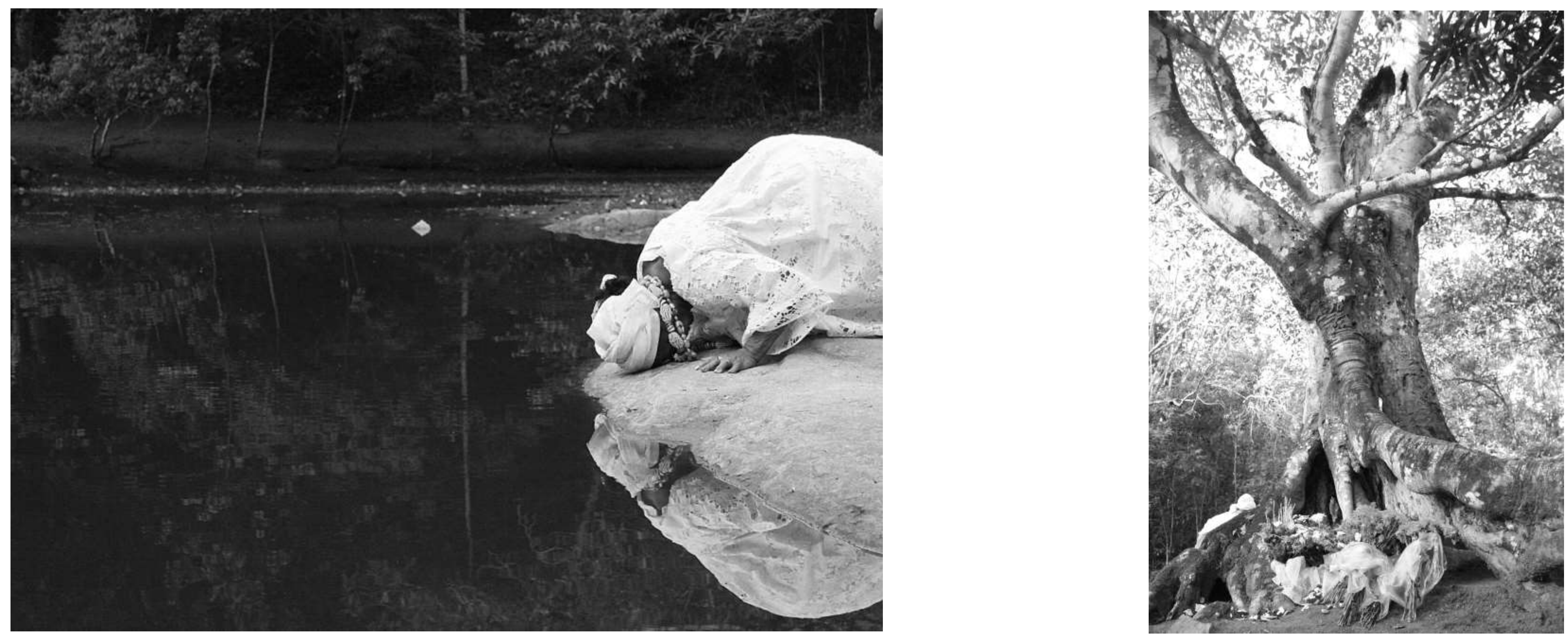


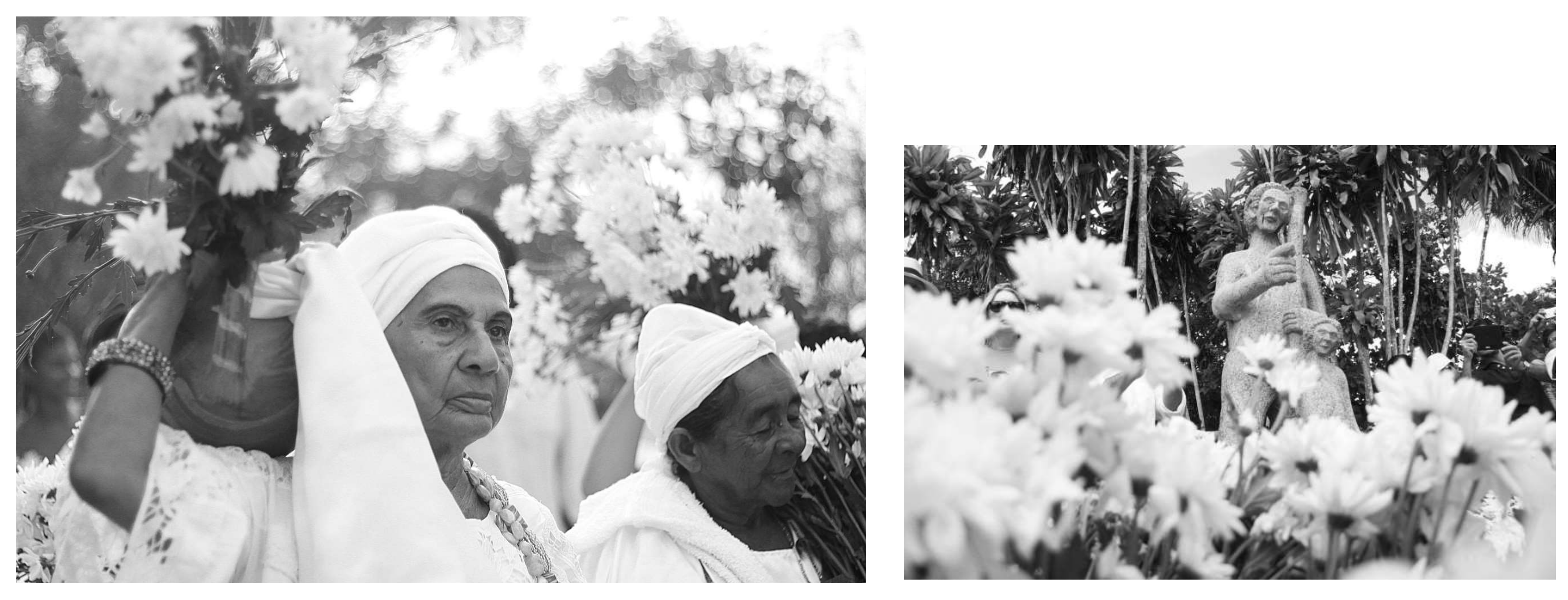




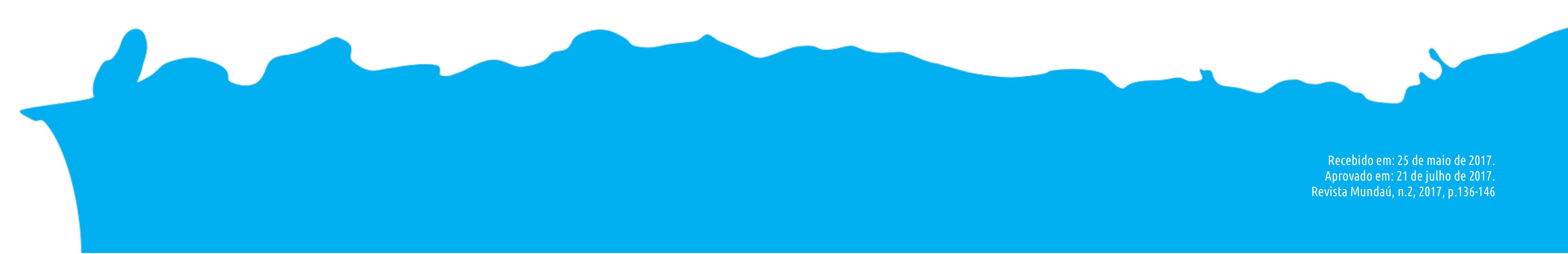

